\title{
Multiple organ dysfunction syndrome in critically ill children: clinical value of two lists of diagnostic criteria
}

\author{
Andréanne Villeneuve, Jean-Sébastien Joyal, François Proulx, Thierry Ducruet, Nicole Poitras \\ and Jacques Lacroix ${ }^{*}$
}

\begin{abstract}
Background: Two sets of diagnostic criteria of paediatric multiple organ dysfunction syndrome (MODS) were published by Proulx in 1996 and by Goldstein in 2005. We hypothesized that this changes the epidemiology of MODS. Thus, we determined the epidemiology of MODS, according to these two sets of diagnostic criteria, we studied the intra- and inter-observer reproducibility of each set of diagnostic criteria, and we compared the association between cases of MODS at paediatric intensive care unit (PICU) entry, as diagnosed by each set of diagnostic criteria, and 90-day all-cause mortality.
\end{abstract}

Methods: All consecutive patients admitted to the tertiary care PICU of Sainte-Justine Hospital, from April 21, 2009 to April 20, 2010, were considered eligible for enrolment into this prospective observational cohort study. The exclusion criteria were gestational age $<40$ weeks, age $<3$ days or $>18$ years at PICU entry, pregnancy, admission immediately after delivery. No patients were censored. Daily monitoring using medical chart ended when the patient died or was discharged from PICU. Mortality was monitored up to death, hospital discharge, or 90 days post PICU entry, whatever happened first. Concordance rate and kappa score were calculated to assess reproducibility. The number of MODS identified with Proulx and Goldstein definitions was compared using 2-by-2 contingency tables. Student's $t$ test or Wilcoxon signed-ranked test was used to compare continuous variables with normal or abnormal distribution, respectively. We performed a Kaplan-Meier survival analysis to assess the association between MODS at PICU entry and 90-day mortality.

Results: The occurrence of MODS was monitored daily and prospectively in 842 consecutive patients admitted to the PICU of Sainte-Justine Hospital over 1 year. According to Proulx and Goldstein diagnostic criteria, 180 (21.4\%) and 314 patients (37.3\%) had MODS over PICU stay, respectively. Concordance of MODS diagnosis over PICU stay was $81.3 \%$ (95\% Cl 78.6-83.9\%), and kappa score was 0.56 (95\% Cl 0.50-0.61). Discordance was mainly attributable to cardiovascular or neurological dysfunction criteria. The proportion of patients with MODS at PICU entry who died within 90 days was higher with MODS diagnosed with Proulx criteria (17.8 vs. $11.5 \%, p=0.038$ ), as well as the likelihood ratio of death (4.84 vs. 2.37). On the other hand, 90-day survival rate of patients without MODS at PICU entry was similar ( 98.6 vs. $98.9 \%(p=0.73)$.

Conclusions: Proulx and Goldstein diagnostic criteria of paediatric MODS are not equivalent. The epidemiology of paediatric MODS varies depending on which set of diagnostic criteria is applied.

Keywords: Critical care, Diagnosis, Intensive care, Mortality, Multiple organ failure, Paediatric

\footnotetext{
*Correspondence: j_lacroix@videotron.ca

Division of Pediatric Critical Care, Department of Pediatrics, Sainte-Justine

Hospital, CHU Sainte-Justine, Room 3431, 3175 Chemin de la

Côte-Ste-Catherine, Montreal, QC H3T 1C5, Canada
}

\section{Springer Open}

(c) 2016 Villeneuve et al. This article is distributed under the terms of the Creative Commons Attribution 4.0 International License (http://creativecommons.org/licenses/by/4.0/), which permits unrestricted use, distribution, and reproduction in any medium, provided you give appropriate credit to the original author(s) and the source, provide a link to the Creative Commons license, and indicate if changes were made. 


\section{Background}

Multiple organ dysfunction syndrome (MODS), a common and deadly condition, is frequently observed in paediatric intensive care units (PICU) [1]. The pathophysiology of MODS is characterized by a severe, systemic, somewhat uncontrolled inflammatory process that leads to multiple organ or system dysfunctions [2]. There is a consensus that MODS should be diagnosed when the dysfunction of at least two organs or systems is simultaneously observed. On the other hand, there is no consensus on the criteria that must be used to diagnose the organ dysfunctions. The diagnostic criteria of MODS changed over time. A first set of diagnostic criteria was proposed in 1986 by Wilkinson [3], which was updated in 1996 by Proulx [4]. In 2005 following an international symposium on sepsis and MODS, experts presented a revised set of diagnostic criteria, authored by Goldstein $[5,6]$. The goal of this 2005 definition was to "identify a reproducible assessment of organ dysfunction that allows for tracking of changes in organ function, both improvement and deterioration".

These sets of diagnostic criteria of paediatric MODS are used in the medical literature. In this study, we determined the epidemiology of MODS, according to the sets of diagnostic criteria of Proulx [4] and Goldstein [5, 6], we studied the intra- and inter-observer reproducibility of each set of diagnostic criteria, and we compared the association between cases of MODS at paediatric intensive care unit (PICU) entry, as diagnosed by each set of diagnostic criteria, and 90-day all-cause mortality.

\section{Methods}

\section{Study population}

All consecutive patients admitted to the tertiary care PICU of Sainte-Justine Hospital (Montreal, Canada), from 21 April 2009 to 20 April 2010, were considered eligible for enrolment into this prospective observational cohort study. The exclusion criteria were: gestational age less than 40 weeks, age less than 3 days or more than 18 years at PICU entry, pregnancy, admission immediately after delivery. The research ethics board of SainteJustine Hospital approved waived consent for this study.

\section{Data collection}

Validated case report forms were filled by PICU research assistants. Time zero for each patient was the day of PICU entry, and daily monitoring using medical chart of each individual case ended when the patient died or was discharged from PICU. We used calendar days (actuarial approach), which means that the time of data collection on day 1 and on day of PICU discharge was shorter than $24 \mathrm{~h}$. Readmission within $24 \mathrm{~h}$ of discharge from PICU was considered as a single PICU stay. Mortality was assessed up to hospital discharge or up to 90 days postPICU entry, whatever happened first.

\section{Definition of MODS}

MODS is defined as the concurrent dysfunction of two or more organs or systems including respiratory, cardiovascular, haematological, neurological, gastrointestinal, hepatic and renal. In this study, we compared the diagnostic criteria suggested in 1996 by Proulx [4] and in 2005 by Goldstein $[5,6]$ (these two sets of diagnostic criteria are detailed in the Additional file 1). In both sets, one to five parameters are used to define each organ dysfunction, which is diagnosed if at least one criterion per organ is met. Some important differences between the two definitions should be underlined. For example, the diagnostic criteria of Proulx include gastrointestinal dysfunction, which was not retained by Goldstein. Moreover, Proulx set of criteria uses two age strata (less than 1 year old or more than 1 year old) to define low blood pressure, bradycardia and tachycardia. Heart rate is not retained in Goldstein set of criteria, but it uses six different strata of age to define normal blood pressure.

Patients with "new MODS" included (1) children with no organ dysfunction at PICU entry who developed two or more concurrent organ dysfunction while in PICU, or (2) children with only one organ dysfunction at PICU entry who subsequently developed concurrently at least another organ dysfunction. "Progressive MODS" was diagnosed when a patient with MODS at PICU entry (i.e. concurrent dysfunction of two or more organ systems) died subsequently or developed at least one additional organ dysfunction.

\section{Statistical analysis}

Descriptive statistics included number and proportions (\%), likelihood ratio, odds ratio, $95 \%$ confidence interval (95\% CI) and mean \pm standard deviation (SD).

To assess intra-observer reproducibility, a research assistant (Marianna Dumitrescu) filled twice, at least 2 months apart, the case report form of 100 randomly selected patients. In order to evaluate inter-observer reproducibility, two different observers (Marianna Dumitrescu and Marilyn Gaudreau) filled the case report form of the same 100 patients. The number of MODS identified with Proulx and Goldstein definitions was compared using 2-by-2 contingency tables. Concordance rate and kappa score (қ) were calculated to assess intraand inter-observer reproducibility of MODS diagnosis with both sets of criteria.

Student's $t$ test or Wilcoxon signed-ranked test was used to compare continuous variables with normal or abnormal distribution, respectively. The association between MODS diagnosis at PICU entry and 90-day 
Table 1 Population description

\begin{tabular}{|c|c|c|c|}
\hline & MODS (Proulx) & $\begin{array}{l}\text { MODS } \\
\text { (Goldstein) }^{\mathbf{b}}\end{array}$ & All patients ${ }^{c}$ \\
\hline & $N=180$ & $N=314$ & $N=842$ \\
\hline \multicolumn{4}{|l|}{ Demographic data } \\
\hline Male & $98(54.5)$ & $168(53.5)$ & $434(51.5)$ \\
\hline Age (months) & $60 \pm 72$ & $64 \pm 70$ & $72 \pm 72$ \\
\hline \multicolumn{4}{|l|}{$\begin{array}{l}\text { Severity of illness at } \\
\text { PICU entry }\end{array}$} \\
\hline PRISM score & $11.4 \pm 7.8$ & $9.2 \pm 7.1$ & $6.0 \pm 5.8$ \\
\hline Daily PELOD score & $10.3 \pm 9.4$ & $8.1 \pm 8.4$ & $4.8 \pm 6.8$ \\
\hline \multicolumn{4}{|l|}{$\begin{array}{l}\text { Main cause of } \\
\text { admissiond }\end{array}$} \\
\hline $\begin{array}{l}\text { Respiratory } \\
\text { disease }\end{array}$ & $76(42.2)$ & $146(46.8)$ & $298(36.4)$ \\
\hline \multicolumn{4}{|l|}{ Shock } \\
\hline $\begin{array}{l}\text { Hypovolemic } \\
\text { shock }\end{array}$ & $10(5.6)$ & $10(3.2)$ & $19(2.5)$ \\
\hline Septic shock & $17(9.6)$ & $19(6.1)$ & $27(3.2)$ \\
\hline $\begin{array}{l}\text { Haemorrhagic } \\
\text { shock }\end{array}$ & $4(2.5)$ & $5(1.6)$ & $5(1.6)$ \\
\hline $\begin{array}{l}\text { Cardiogenic } \\
\text { shock }\end{array}$ & $13(7.5)$ & $13(4.2)$ & $15(1.8)$ \\
\hline $\begin{array}{l}\text { Congenital heart } \\
\text { disease }\end{array}$ & $29(16.3)$ & $39(12.6)$ & $77(9.2)$ \\
\hline Bacterial infection & $70(39.1)$ & $125(39.9)$ & $237(28.2)$ \\
\hline Viral infection & $46(25.8)$ & $97(31.1)$ & $203(24.2)$ \\
\hline \multicolumn{4}{|l|}{ Trauma } \\
\hline Polytraumatism & $4(2.2)$ & $11(3.5)$ & $18(2.4)$ \\
\hline $\begin{array}{l}\text { Severe head } \\
\text { trauma }\end{array}$ & $6(3.3)$ & $10(3.1)$ & $11(1.3)$ \\
\hline Burn & $2(1.1)$ & $2(0.6)$ & $5(0.6)$ \\
\hline \multicolumn{4}{|l|}{ Surgery } \\
\hline $\begin{array}{l}\text { Post-cardiac } \\
\text { surgery }\end{array}$ & $22(12.3)$ & $38(12.1)$ & $105(12.5)$ \\
\hline $\begin{array}{l}\text { Other surgery } \\
\text { (planned) }\end{array}$ & $17(9.5)$ & $33(10.5)$ & $146(17.4)$ \\
\hline $\begin{array}{l}\text { Other surgery } \\
\text { (unplanned) }\end{array}$ & $14(7.8)$ & $24(7.7)$ & $63(7.5)$ \\
\hline $\begin{array}{l}\text { Other reasons for } \\
\text { admission }\end{array}$ & 91 (50.6) & $145(46.2)$ & $368(43.8)$ \\
\hline \multicolumn{4}{|l|}{$\begin{array}{l}\text { Specific treatment } \\
\text { during PICU stay }\end{array}$} \\
\hline ECMO & $7(3.9)$ & $7(2.3)$ & $7(0.8)$ \\
\hline Haemofiltration & $6(3.3)$ & $7(2.3)$ & $7(0.8)$ \\
\hline Haemodialysis & $10(5.5)$ & $9(2.9)$ & $15(1.5)$ \\
\hline $\begin{array}{l}\text { At least } 1 \text { red cell } \\
\text { transfusion }\end{array}$ & $91(50.6)$ & $101(32.2)$ & $142(16.9)$ \\
\hline
\end{tabular}

Number (\%) or mean \pm SD

ECMO extracorporeal membrane oxygenation, MODS multiple organ dysfunction syndrome, PELOD paediatric logistic organ dysfunction, PICU paediatric intensive care unit, $P R I S M$ paediatric risk of mortality

a MODS (Proulx): cases of MODS diagnosed during PICU stay, using diagnostic criteria advocated by Proulx in 1996 [4]

b MODS (Goldstein): cases of MODS diagnosed during PICU stay, using diagnostic criteria advocated by Goldstein in $2005[5,6]$

c Include patients with and without MODS

${ }^{d}$ There were many causes of admission in some patients mortality was assessed by performing a Kaplan-Meier survival analysis. No patients were censored: all were monitored up to death, hospital discharge or 90 days post-PICU entry, whatever happened first.

Type 1 error was fixed at $5 \%$; $p$ value $<0.05$ was considered statistically significant. The data were analysed using the statistical software SAS program (SAS, release 9.3, SAS Institute Inc., Cary, NC, USA).

\section{Results}

Over the 1-year study period, there were 913 consecutive PICU admissions at Sainte-Justine Hospital. We excluded 71 because of gestational age $<40$ weeks $(n=41)$, because of age at PICU entry $<3$ days or $>18$ years $(n=40)$ or because the patient was admitted immediately after delivery $(n=1)$; more than one exclusion criterion was noted in some patients. Demographic information about the 842 PICU patients retained in the study is reported in Table 1.

\section{Epidemiology}

Using Proulx and Goldstein diagnostic criteria, the number of patients with MODS during PICU stay was $180(180 / 842=21.4 \%)$ and $314(37.3 \%)$, respectively (Table 1). We observed new MODS in 56 $(56 / 842=6.7 \%)$ and 65 children $(7.7 \%)$ and progressive MODS in 109 (12.9\%) and 104 patients (12.4\%), respectively. The proportion of MODS diagnosed at PICU entry that developed into progressive MODS was $87.9 \%$ (109/124) and $41.8 \%(104 / 249)$ with Proulx and Goldstein criteria, respectively. The incidence rate of new and progressive MODS was 19.6 and $20.1 \%$ with Proulx and Goldstein definitions, respectively.

\section{Reproducibility}

Reproducibility was tested in 100 patients. The interobserver concordance rate of MODS diagnosis was $93 \%$ (kappa: 0.84; 95 \% CI 0.72-0.95) using Proulx criteria and 93 \% (kappa: 0.86; 95 \% CI 0.76-0.96) using Goldstein criteria. Intra-observer reproducibility was $89 \%$ (kappa: $0.74 ; 95$ \% CI $0.59-0.88$ ) vs. 90 \% (kappa: 0.80; 95 \% CI $0.68-0.92)$.

\section{Concordance of diagnostic criteria}

We calculate concordance and kappa score to estimate whether MODS or a given organ dysfunction was diagnosed twice or not diagnosed twice by the same observer in the same patients, using in the same patients the two sets of diagnostic criteria (inter-tests reproducibility). Concordance in 842 patients between Proulx and Goldstein MODS diagnosis at PICU entry was $81 \%(95 \% \mathrm{CI}$ $79-84 \%$ ) and the kappa score was 0.49 (95\% CI $0.43-$ 0.56) (Table 2). The concordance and kappa score for new 
Table 2 Inter-test reproducibility of two sets of diagnostic criteria of MODS in 842 consecutive PICU patients

\begin{tabular}{|c|c|c|c|c|c|}
\hline & \multicolumn{5}{|c|}{ Diagnosis of MODS or organ dysfunction in 842 patients } \\
\hline & Proulx, patients ${ }^{\mathrm{a}}$ & Goldstein patients $^{\mathbf{b}}$ & Concordance $^{c}$ & $p$ value & Kappa score $e^{c, d}$ \\
\hline \multicolumn{6}{|l|}{ MODS during PICU stay } \\
\hline 1. MODS at PICU admission & $124(14.7 \%)$ & $249(29.6 \%)$ & $81 \%$ & $<0.001$ & $0.49(0.43-0.56)$ \\
\hline Progressive MODS & $109(12.9 \%)$ & $104(12.4 \%)$ & $89 \%$ & $<0.001$ & $0.50(0.42-0.59)$ \\
\hline 2. New MODS & $56(6.7 \%)$ & $65(7.7 \%)$ & $93 \%$ & $<0.001$ & $0.50(0.39-0.61)$ \\
\hline MODS during PICU stay $(1+2)$ & $180(21.4 \%)$ & $314(37.3 \%)$ & $80 \%$ & $<0.001$ & $0.56(0.50-0.61)$ \\
\hline \multicolumn{6}{|l|}{ Organ dysfunction during PICU stay } \\
\hline Respiratory & $317(37.7 \%)$ & $373(44.3 \%)$ & $92 \%$ & $<0.001$ & $0.85(0.81-0.88)$ \\
\hline Cardiovascular & 125 (14.9\%) & $15(1.8 \%)$ & $86 \%$ & $<0.001$ & $0.17(0.09-0.25)$ \\
\hline Haematological & 93 (11.1\%) & $122(14.5 \%)$ & $90 \%$ & $<0.001$ & $0.55(0.46-0.63)$ \\
\hline Neurological & 150 (17.8\%) & 428 (50.8 \%) & $67 \%$ & $<0.001$ & $0.34(0.30-0.39)$ \\
\hline Gastrointestinal & $13(1.5 \%)$ & Not applicable & - & - & - \\
\hline Hepatic & 65 (7.7\%) & 107 (12.7\%) & $93 \%$ & $<0.001$ & $0.62(0.54-0.71)$ \\
\hline Renal & $23(2.7 \%)$ & 25 (3.0 \%) & $99 \%$ & $<0.001$ & $0.91(0.83-0.99)$ \\
\hline
\end{tabular}

$95 \% \mathrm{Cl} 95 \%$ confidence interval

MODS multiple organ dysfunction syndrome, PICU paediatric intensive care unit

a Diagnostic criteria of MODS advocated by Proulx in 1996 [4]

b Diagnostic criteria of MODS advocated by Goldstein in $2005[5,6]$

c Concordance and kappa score estimate whether a given organ dysfunction was diagnosed twice or not diagnosed twice by the same observer in the same patients (inter-tests reproducibility), using in the same patients the two sets of diagnostic criteria of Proulx and Goldstein

${ }^{d}$ According to Kramer [21], a kappa score is considered slight if $<0.2$, fair if between 0.2 and 0.4 , moderate if between 0.4 and 0.6 , substantial if between 0.6 and 0.8 and almost perfect if $>0.8$

e Progressive MODS can happen only in patients with MODS at PICU admission

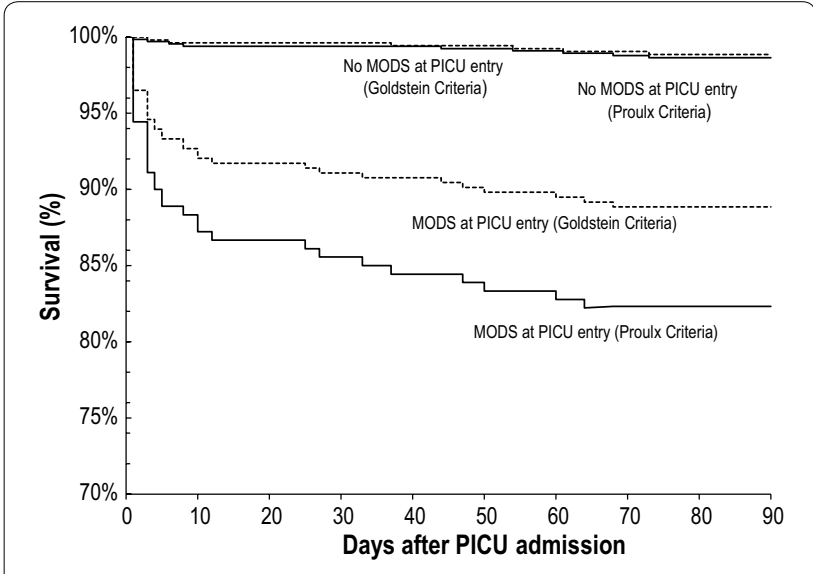

Fig. 1 Survival analysis. Survival among 842 children with or without MODS at PICU entry, as defined by Proulx [4] or by Goldstein [5, 6]; no patient was lost or censored. There are four Kaplan-Meier curves: (1) patients without MODS, as diagnosed by the Goldstein diagnostic criteria (upper hatched curve); (2) patients without MODS, as diagnosed using Proulx diagnostic criteria (upper plain curve);

(3) patients with MODS, as diagnosed by the Goldstein diagnostic criteria (lower hatched curve); (4) patients with MODS, as diagnosed by the Proulx diagnostic criteria (lower plain curve). There is a statistically significant difference between the two survival curves of patients with MODS according to Proulx and Goldstein definitions (lowest two curves) $(p<0.001)$. MODS multiple organ dysfunction syndrome, PICU paediatric intensive care unit
(93\%) and progressive MODS (89\%) were high, with similar kappa scores 0.50 . The concordance of the organ dysfunctions ranges from $67 \%$ (neurological) to $99 \%$ (renal dysfunction); the kappa scores range from 0.17 (cardiovascular) to 0.91 (renal dysfunction).

\section{Mortality associated with MODS}

Forty-two patients $(42 / 842=5.0 \%)$ died, 28 $(28 / 42=66.7 \%)$ during their PICU stay and $41(97.6 \%)$ within 90 days after PICU entry (one patient died after more than 90 days). The 90-day all-cause mortality was higher when MODS was diagnosed at PICU entry using Proulx criteria ( 17.8 vs. $11.5 \%, p=0.038$ ); likewise, the likelihood ratio of death in patients with MODS at PICU entry was higher with Proulx criteria (4.84 vs. 2.37). On the other hand, the 90-day survival rate of patients without MODS at PICU entry was similar (98.6 vs. $98.9 \%$ $(p=0.73)$. There was a statistically significant difference between the survival curves of the two definitions for patients with MODS $(p<0.001)$ (Fig. 1).

\section{Discussion}

\section{Epidemiology}

MODS is a syndrome. By definition, a syndrome is a group of symptoms and signs that consistently occur 
together or a condition characterized by a set of associated symptoms and signs that is so common that it cannot be attributed to hazard. In theory, the diagnosis of a syndrome like MODS could be based on clinical and/or laboratory data. In practice, we do not have a pathognomonic laboratory test that can be used as a gold standard to diagnose MODS. Therefore, MODS is presently a clinical diagnosis that is based on lists of criteria.

Two sets of diagnostic criteria are currently used in the medical literature: one was published by Proulx [4] and the other one by Goldstein $[5,6]$. In our hands, the incidence of MODS was 21.4 and $37.3 \%$ with the diagnostic criteria of Proulx and Goldstein, respectively. This important difference in the incidence rate of MODS diagnosed by these two sets of criteria is probably attributable to different incidence rates of cardiovascular (14.9 vs. $1.8 \%$ ) and neurological dysfunction (17.8 vs. $50.8 \%$ ).

Our study reports many other important epidemiological data on paediatric MODS. In the literature, the prevalence and incidence rate of MODS reported in critically ill children while in PICU range from 6 to $71 \%[7,8]$. Using Proulx definition, Tantalean [9] reported MODS in $56.5 \%$ of patients during their PICU stay; $84.6 \%$ of these MODS were present at PICU entry. Applying the same criteria, we observed a much lower prevalence $(21.4 \%)$ of MODS at PICU entry.

Using Goldstein diagnostic criteria, Typpo [10] reported a prevalence of MODS at PICU entry of $18.6 \%$; we noted a prevalence of $37.3 \%$. This difference might be attributable to different case-mix: Typpo and colleagues excluded patients younger than 1 month of age, while we did not; moreover, they excluded all patients from all hospitals where more than $10 \%$ missing values for MODS variables were missing.

We checked whether the prevalence in PICU of the individual organ dysfunction was similar with the two sets of criteria (Table 2). Otherwise than the cardiovascular dysfunction, the prevalence during PICU stay of all organ dysfunctions was higher with Goldstein than with Proulx criteria. Using concordance and kappa score, we also checked whether both sets of criteria diagnosed the same organ dysfunction in the same patients; inter-test reproducibility was poor in cardiovascular (kappa $=0.17$; $95 \%$ CI 0.09-0.25) and neurological dysfunction (0.34; $95 \%$ CI 0.30-0.39). This poor inter-test reproducibility is probably attributable to different definitions of cardiovascular and neurological dysfunction. The low prevalence of cardiovascular dysfunction as diagnosed with Goldstein criteria $(1.8 \%)$ is probably explained by the fact that a patient should receive a fluid bolus $(\geq 40 \mathrm{ml} / \mathrm{kg})$ to be considered as having a cardiovascular dysfunction. This criterion may exclude patients in cardiogenic shock or with congenital heart disease treated with inotropes for which large fluid boluses are avoided. The prevalence of neurological dysfunction was lower with Proulx than with Goldstein criteria (17.8 vs. $50.8 \%$ ); this is probably explained by more severe criteria with the former (Glasgow coma score $<5$ or fixed dilated pupils) than with the latter (Glasgow coma score $\leq 11$ or acute change in mental status with a change in Glasgow coma score $\geq 3$ points from abnormal baseline). Gastrointestinal dysfunction is only considered in the set of diagnostic criteria of Proulx. It is rare $(1.5 \%)$ and it did not contribute importantly to the observed discordance. The utility of including gastrointestinal dysfunction in MODS definition is questionable.

Diagnosis of MODS using Proulx and Goldstein criteria is not interchangeable. Weiss [11] reported a sevenfold difference in the frequency of sepsis, using different definitions. Hence, any changes to the diagnostic criteria of a syndrome like MODS or a disease like sepsis will inevitably change their epidemiology. It is not rare to read a paper where a "modified" or "adapted" definition of a set of diagnostic criteria is used; this practice must be banned unless the new definition is well validated and its epidemiology well compared to the epidemiology of previous definitions. Practitioners and investigators must carefully account for variations in diagnostic methods when reviewing and interpreting the literature, or preparing a clinical trial.

New and progressive MODS was used as a composite outcome measure in many randomized controlled trials that enrolled critically ill patients [12-14]. Leteurtre [15] determined the incidence rate of MODS in 3669 consecutive patients enrolled in two European PICUs: the incidence rate of new and progressive MODS was 5.5 and $4.7 \%$, respectively (total: $10.2 \%$ ). Weiss [16] reported that $30 \%$ of children subsequently developed new or progressive MODS after sepsis recognition. In our study, the incidence rate of new and progressive MODS was 19.6 and $20.1 \%$ with Proulx and Goldstein definitions, respectively, which is quite similar; this suggests that using one rather than the other set of diagnostic criteria of organ dysfunction would not change the sample size of a randomized controlled trial where the primary outcome measure is new or progressive MODS. On the other hand, the incidence rate of new or progressive MODS (range 10.2 and $20.1 \%$ ) is at least three times higher than the incidence rate of PICU mortality $(2.7 \%$; site range 1.3-5.0 \%) reported by Pollack in 2015 in seven American sites [17]. Thus, choosing a composite outcome that includes new and progressive MODS-progressive MODS containing all deaths-rather than mortality alone as the primary outcome measure of a randomized controlled trial conducted in PICU should decrease significantly the sample size required to complete the trial. 


\section{Test validation}

A set of diagnostic criteria is a test that is used to discriminate patients with or without a disease. The best way to validate a test is to determine its sensitivity and specificity, which required a gold standard able to classify patients in the right group (with or without the disease). However, there is presently no gold standard that can be used to differentiate patients with or without MODS. Therefore, we were unable to compare the sensitivity and specificity of the two sets of diagnostic criteria to diagnose MODS, using a gold standard. This is why this study does not tell us if the discriminative value of one set of diagnostic criteria is better that the other.

However, sensitivity and specificity are not the only parameters that can be used to validate a test: reproducibility is another important quality of a test $[18,19]$. Juskewitch [20] reported an inter-observer agreement to diagnose paediatric cases of systemic inflammatory response syndrome of $88 \%$ (95\% CI 74-94) with a kappa score of 0.75 (95\% CI 0.59-0.92), which is considered "substantial agreement" [21]. We study intra- and inter-observer reproducibility of two sets of diagnostic criteria [5, 6]. The inter-observer agreement of MODS diagnosis was 93 \% (kappa: 0.84; $95 \%$ CI 0.72-0.95) using Proulx criteria and 93 \% (kappa: 0.86; $95 \%$ CI 0.76-0.96) using Goldstein criteria. Intra-observer reproducibility was 89 \% (kappa: 0.74; 95 \% CI 0.59-0.88) vs. 90 \% (kappa: 0.80; 95 \% CI 0.68-0.92). Thus, inter- and intra-observer reproducibility of both sets of diagnostic criteria was almost similar and would be considered "almost perfect" by experts in epidemiology [21].

\section{Association between MODS and outcomes}

A diagnosis is more useful if it is associated with predictable outcomes [22]. MODS is associated not only with shortterm mortality $[10,15,23]$, but also with long-term adverse events, such as poor functional outcomes [10]. MODS is diagnosed in $66-91.5 \%$ of patients who die in $\operatorname{PICU}[9,10]$. In the literature, the mortality rate of critically ill children having MODS ranges from 10 to $57 \%[8,10]$. Tantalean [9], using Proulx diagnostic criteria, reported a $41.6 \%$ mortality rate in children with MODS. Using Proulx criteria, we report a 90-day mortality rate of $19.8 \%$ in patients with MODS at PICU entry, while it was $11.5 \%(p=0.038)$ using Goldstein criteria. On the other hand, the risk of death was lower in patients without MODS at PICU entry, irrespective of the definition used (Fig. 1). MODS remains highly associated with mortality in critically ill children, regardless of the set of diagnostic criteria chosen.

\section{Strengths and limitations}

The prospective design of our study is a considerable strength. Moreover, we enrolled consecutive PICU patients over a 1-year period, which enhances representativeness.
Our study has several limitations. First, one can wonder whether it is relevant to compare two different sets of diagnostic criteria that were published 10 years apart. We believe that it is relevant because the relationship between these two sets has never been evaluated. Moreover, both sets of diagnostic criteria-Proulx and Goldstein-are presently used [24-26]. We showed that these two sets do not diagnose MODS in the same patients, something that is frequently ignored. Second, we completed a single-centre study, which limits its external validity. However, when comparing severity of illness indicators and mortality rates, our PICU seems comparable to other level III multidisciplinary university-affiliated centres. Third, this study does not determine which definition-Proulx or Goldstein-should be used to study MODS in critically ill children. However, it provides information on reproducibility and likelihood of 90-day mortality that should allow investigators and practitioners to choose the most appropriate set of diagnostic criteria of MODS, given their scientific or clinical objectives.

\section{Conclusions}

Different prevalence and incidence of MODS in different papers might be attributable to many causes: study design (retro- vs. prospective), different case-mix of patients, secular trends, detection bias, reporting bias, different sources of data and chance; it can also be attributable to the use of different diagnostic criteria [27]. Proulx [4] and Goldstein $[5,6]$ suggested two different sets of diagnostic criteria of paediatric MODS. These two sets are not equivalent. Both definitions have good inter- and intra-observer reproducibility, and both are closely associated with short-term mortality. However, the association between MODS diagnosed with Proulx criteria and 90-day mortality was higher than with Goldstein criteria.

The diagnostic criteria of MODS can be improved; we can look for a better alignment between diagnosis of MODS and its pathophysiology (uncontrolled systemic inflammation) and/or a better predictive value (mortality, post-PICU sequelae, quality of life). Finding a test or a group of tests that can reliably support the diagnosis of MODS would be very useful.

\section{Additional file}

Additional file 1. Supplementary material on the multiple organ dysfunction syndrome: sets of diagnosticcriteria suggested by Proulx et al. [4] and by Goldstein et al. [5, 6].

\section{Abbreviations}

APTT: activated partial thromboplastin time; ARDS: acute respiratory distress syndrome; $\mathrm{Cl}$ : confidence interval; ECMO: extracorporeal membrane 
oxygenation; ICU: intensive care unit; MODS: multiple organ dysfunction syndrome; OR: odds ratio; PELOD: paediatric logistic organ dysfunction; PICU: paediatric ICU; PRISM: paediatric risk of mortality; PT: prothrombin time.

\section{Authors' contributions}

AV, JSJ, FP and TD wrote the research protocol. Enrolment of patients and data collection were done by AV, NP and JL. Statistical analysis was done by AV, TD and JL. All authors read and approved the final manuscript.

\section{Competing interests}

The authors declare that they have no competing interests.

\section{Source of funding}

Supported by Fonds de la recherche en santé du Québec (Grant 24460).

Received: 14 December 2015 Accepted: 12 April 2016

Published online: 29 April 2016

\section{References}

1. Proulx F, Leteurtre S, Leclerc F, Lacroix J, Van den Berghe G, Vanasse M. Syndrome de défaillance multiviscérale. In: Lacroix J, Gauthier M, Hubert $P$, Leclerc F, Gaudreault $P$, editors. Urgences et soins intensifs pédiatriques 2e édition. 2e ed. Montréal et Paris: Éditions du CHU Sainte-Justine \& Masson; 2007. p. 143-65.

2. Despond O, Proulx F, Carcillo J, Lacroix J. Pediatric sepsis and multiple organ dysfunction syndrome. Curr Opin Pediatr. 2001;13:247-53.

3. Wilkinson JD, Pollack MM, Ruttimann VE, Glass NL, Yeh TS. Outcome of pediatric patients with multiple organ system failure. Crit Care Med. 1986;14:271-4

4. Proulx F, Fayon M, Farrell CA, Lacroix J, Gauthier M. Epidemiology of sepsis and multiple organ dysfunction syndrome in children. Chest. 1996;109:1033-7.

5. Goldstein B, Giroir B, Randolph A. Values for systolic blood pressure. Pediatr Crit Care Med. 2005;6:500-1.

6. Goldstein B, Giroir B, Randolph A, the International Consensus Conference on Pediatric Sepsis. International pediatric sepsis consensus conference: definitions for sepsis and organ dysfunction in pediatrics. Pediatr Crit Care Med. 2005;6:2-8.

7. Tan GH, Tan TH, Goh DYT, Yap HK. Risk factors for predicting mortality in a paediatric intensive care unit. Ann Acad Med Singap. 1998;27:813-8.

8. Goh AYT, Lum LCS, Chan PWK. Paediatric intensive care in Kuala Lumpur, Malaysia: a developing subspecialty. J Trop Pediatr. 1999:45:362-4.

9. Tantalean JA, Leon JL, Santos AA, Sanchez E. Multiple organ dysfunction syndrome in children. Pediatr Crit Care Med. 2003:4:181-5.

10. Typpo KV, Petersen NJ, Hallman M, Markovitz BP, Mariscalco M. Day 1 multiple organ dysfunction syndrome is associated with poor functional outcome and mortality in the pediatric intensive care unit. Pediatr Crit Care Med. 2009;10:562-70.

11. Weiss SL, Parker B, Bullock ME, Swartz S, Price C, Wainwright MS, Goodman DM. Defining pediatric sepsis by different criteria: discrepancies in populations and implications for clinical practice. Pediatr Crit Care Med. 2012;13:e219-26
12. Lacroix J, Hébert PC, Hutchison JH, Hume H, Tucci M, Ducruet T, Gauvin F, Collet JP, Toledano BJ, Robillard P, et al. Transfusion strategies for patients in pediatric intensive care units. N Engl J Med. 2007;356:1609-19.

13. Lacroix J, Hébert PC, Fergusson DA, Tinmouth A, Cook DJ, Marshall JC, Clayton L, Mclntyre L, Callum J, Turgeon AF, et al. Age of transfused blood in critically ill adults. N Engl J Med. 2015;372:1410-8.

14. Steiner ME, Ness PM, Assmann SF, Triulzi DJ, Sloan SR, Delaney M, Granger S, Bennett-Guerrero E, Blajchman MA, Scavo V, et al. Effects of red-cell storage duration on patients undergoing cardiac surgery. N Engl J Med. 2015;372:1419-29.

15. Leteurtre S, Deken V, Lacroix J, Duhamel A, Leclerc F. Daily estimation of the severity of organ dysfunctions in critically ill children by using the PELOD-2 score. Crit Care. 2015;19:324.

16. Weiss SL, Fitzgerald JC, Pappachan J, Wheeler D, Jaramillo-Bustamante JC, Salloo A, Singhi SC, Erickson S, Roy JA, Bush JL, et al. Global epidemiology of pediatric severe sepsis: the Sepsis PRevalence, OUtcomes, and Therapies study. Am J Respir Crit Care Med. 2015;191:1147-57.

17. Pollack MM, Holubkov R, Funai T, Berger JT, Clark AE, Meert K, Berg RA, Carcillo J, Wessel DL, Moler F, et al. Simultaneous prediction of new morbidity, mortality, and survival without new morbidity from pediatric intensive care: a new paradigm for outcomes assessment. Crit Care Med. 2015:43:1699-709.

18. Riegelman RK. Studying a study and testing a test. Boston: Little, Brown \& Co; 1981

19. Sackett DL, Haynes RB, Tugwell P. Clinical epidemiology. Boston: Little, Brown \& Co; 1985.

20. Juskewitch JE, Prasad S, Salas CF, Huskins WC. Reliability of the identification of the systemic inflammatory response syndrome in critically ill infants and children. Pediatr Crit Care Med. 2012;13:e55-7.

21. Kramer M, Feinstein AR. Clinical biostatistics. LIV. The biostatistics of concordance. Clin Pharmacol Ther. 1981:29:111-23.

22. Kaukonen KM, Bailey M, Pilcher D, Cooper DJ, Bellomo R. Systemic inflammatory response syndrome criteria in defining severe sepsis. N Engl J Med. 2015;372:1629-38

23. Leclerc F, Leteurtre S, Duhamel A, Grandbastien B, Proulx F, Martinot A Gauvin F, Vu Nam T, Hubert P, Lacroix J. Cumulative influence of multiple organ dysfunction syndrome and "septic" state on mortality of critically ill children. Am J Respir Crit Care Med. 2005;171:348-53.

24. Du Pont-Thibodeau G, Tucci M, Robitaille R, Ducruet T, Lacroix J: Determinants of platelet transfusion in a paediatric critical care unit. In: 7th world congress on pediatric intensive and critical care: 2014; Istanbul (Turqey).

25. Demaret P, Tucci T, Karam O, Ducruet T, Trottier H, Lacroix J. Clinical outcomes associated with red blood cell transfusions in critically ill children: a one-year prospective study. Pediatr Crit Care Med. 2015:16:505-14.

26. Kleiber N, Lefebvre É, Gauvin F, Tucci M, Robitaille N, Trottier H, Jouvet P, Ducruet T, Poitras N, Lacroix J, et al. Respiratory dysfunction associated with red blood cell transfusion in critically ill children: a prospective cohort study. Pediatr Crit Care Med. 2015;16:325-34.

27. Fontela P, Lacroix J. Sepsis or SEPSIS: does it make a difference? Pediatr Crit Care Med. 2014;15:893-4.

\section{Submit your manuscript to a SpringerOpen ${ }^{\circ}$ journal and benefit from:}

- Convenient online submission

- Rigorous peer review

- Immediate publication on acceptance

- Open access: articles freely available online

- High visibility within the field

- Retaining the copyright to your article

Submit your next manuscript at springeropen.com 